Tackling Biology Projects 
Dedicated to the memory of my father

Alexander Mackay Craig 


\section{Tackling Biology Projects}

\section{Marilyn Anne Wedgwood}

BSc, MSc, PhD, CBiol, MIBiol

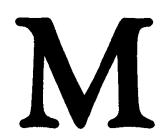

MACMILLAN 
(C) Marilyn Anne Wedgwood 1987

All rights reserved. No reproduction, copy or transmission of this publication may be made without written permission.

No paragraph of this publication may be reproduced, copied or transmitted save with written permission or in accordance with the provisions of the Copyright, Designs and Patents Act 1988, or under the terms of any licence permitting limited copying issued by the Copyright Licensing Agency, 33-4 Alfred Place, London WC1E 7DP.

Any person who does any unauthorised act in relation to this publication may be liable to criminal prosecution and civil claims for damages.

First published 1987

Reprinted 1991

Published by

MACMILLAN EDUCATION LTD

Houndmills, Basingstoke, Hampshire RG21 2XS

and London

Companies and representatives

throughout the world

British Library Cataloguing in Publication Data

Wedgwood, Marilyn

Tackling biology projects. - (Tackling

projects)

1. Biology

I. Title II. Series

574 QH308.7

ISBN 978-0-333-42869-6 ISBN 978-1-349-09131-7 (eBook)

DOI 10.1007/978-1-349-09131-7 


\section{Contents}

Preface

How to Use this Book

Tackling the Project - A Summarised Step by Step Guide

$v i i$

$i x$

$x$

1 General Background to a Biology Project

1.1 General background

1.2 The development of a project

1.3 What is expected of the student?

1.4 The supervisor's role in the project

1.5 Choosing a project

2 The Investigation

2.1 The place of the investigation within a project 14

2.2 Basic characteristics of investigations 15

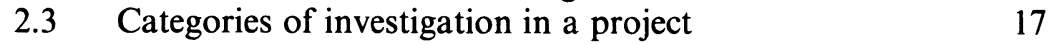

2.4 Choosing an investigation 20

2.5 Formulating the aims of an investigation precisely 22

2.6 Expansion from the aim to increase results (with minimum effort) 25

2.7 Final preparation before contemplating the design 29

3 Designing an Investigation 31

3.1 General aspects 32

3.2 Identifying the steps in an investigation 32

3.3 Deciding on the techniques to be employed 35

3.4 A consideration of the analysis of results 37

3.5 Controls, samples and replication 42

3.6 The final design $\quad 50$

4 The Practical Work 51

4.1 Some general considerations $\quad 52$

4.2 Preliminary investigations 52

4.3 Planning and organisation 57

4.4 Doing the practical work $\quad 60$

4.5 A strategy for overcoming difficulties 62 
5 Results

5.1 Introduction 66

5.2 What is a result? 66

5.3 What kind of results can you expect from your project? 67

5.4 When are there enough results? 69

5.5 Increasing your chances of obtaining results 70

5.6 What you can do if you cannot get any results 71

5.7 The analysis and interpretation of results 73

5.8 Using the results for subsequent investigations 79

6 Using and Applying Statistics 81

6.1 A basic approach to using and applying statistics $\quad 82$

6.2 Statistical techniques for summarising data 85

6.3 Significance tests for making comparisons between sets of data to test for significant differences

6.4 Parametric tests for comparing means and their nonparametric, rank order statistics, equivalent

6.5 Chi square tests for testing for significant differences with nominal data

6.6 Understanding how to use a significance test 98

6.7 Regression and correlation

6.8 A word of warning about applying statistics

\section{Using the Literature}

7.1 General points and advice 106

7.2 Sources of information 106

7.3 Finding the information from the literature 110

7.4 Some advice in using the literature 113

\section{Writing the Project Report}

8.1 The importance of writing a good project report 118

8.2 General practical points to be aware of before you start 119

$\begin{array}{ll}\text { 8.3 Maintaining coherence in the project report } & 121\end{array}$

8.4 When and where to start

8.5 Writing the Methods section 125

$\begin{array}{ll}8.6 & \text { Writing the Results section } \\ 8.7 & 127\end{array}$

8.7 Writing the Introduction and Discussion 129

8.8 Showing you know the literature in a project report 137

8.9 Demonstrating a critical awareness of your own and other researchers' work in the project report

8.10 Writing up the remaining sections 


\section{Preface}

I wrote this book in the hope that it would give direct help to students who have to complete a practical project in Biology - thus fulfilling an often expressed desire by students for more guidance. The idea evolved as I witnessed the difficulties and problems many students faced when embarking on a project, and as I recognised that such problems and difficulties were similar between different groups of students and recurred each new academic year. Furthermore it became clear to me from the comments made by supervisors and examiners that there existed many common mistakes by students in the approach to the project work across a range of different types of projects, and students too often commented that they would have appreciated some clear, straightforward, practical guidance to enhance the experience gained.

This book therefore aims to give straightforward, easily accessible and relevant help and guidance on how to approach and do a Biology practical project successfully. It is written primarily for undergraduate students on BSc, GIBiol (MIBiol), B/TEC HND and HNC courses, though postgraduates embarking on an MSc or PhD might also find it useful.

As I wrote the book I tried to ensure that the advice offered was consistent with the generally established view of sound scientific practice, took account of the common problems and mistakes made by students and kept sight of the fact that the project is an assessed part of a course. Obviously, in a book of this size and approach it is impossible to give a full examination of many of the issues but there are other more detailed and specialised texts which can be referred to. I would, however, be most happy to receive comments on the usefulness of the book and any suggestions for modifications and improvements.

A bibliography has not been prepared as it was felt to be generally inappropriate within the context of the aims of this book. There are many related areas which could be pursued through the subject index of a library under such headings as: experimental design; experimental methods; scientific methods; writing reports; practical investigation; projects in Biology; and philosophy of science.

I am grateful to the many students at Manchester Polytechnic who acted as 'guinea pigs' for testing out some of the ideas - often unwittingly, and for their comments and reactions to the work - particularly Carl Brown and Craig MacKerness for their constructive criticism. I 
would particularly like to thank Mantz Yorke for his encouragement and patience in ploughing carefully through the early manuscripts and Vic Pentreath for his valuable criticism and advice which concentrated and focussed my thoughts. I am grateful to Roger Williams for reading, advising on, and correcting the chapter on statistics, to Michael Head, John Gaffney and Derek Gordon for comments on the early chapters, and to Jean Higginbottom and Tina Theis for their advice on chapter 7. I would like to convey my special thanks to my friend and colleague, Maureen Dawson, who offered support and advice throughout with good humour and good sense, and who generously read and made useful comments on the final manuscript, and to my husband Barry for his continual encouragement and reassurance which sustained me through the various crises of confidence, so enabling me to complete the work. I would like to thank Christine Foster who typed the final manuscript caringly and carefully, and Marion Sibbit for patiently typing some of the earlier drafts - each of whom worked from some untidy and almost illegible scripts. Last but not least, I would like to thank Gary Larvin for the good humoured drawings. 


\section{How to Use this Book}

The flow diagram which follows gives you a summarised step by step guide to completing your Biology project. Use the flow diagram as an overall guide and main point of reference as you tackle your project.

Four stages to the project are identified in the flow diagram: Initial Preparation; Design the Investigation; Do the Practical Work; and Write the Project Report. For each stage there is a series of tasks which you will have to complete. References to sections in the book are given for each of these tasks, to help you. The outcomes resulting from completing the tasks are identified in the flow diagram.

Each chapter of the book is divided into sections and the sections have two main styles of text. There are checklists of direct practical advice for easy and quick reference. Other text in the section then discusses some of the issues in more detail.

At the beginning of the book (sections 1.1, 1.2, 2.1, 2.2 and 2.3) some more general aspects of the project are discussed. They are worthwhile reading for gaining a fuller understanding of the project and for using other parts of the book. However, they are short on the direct practical advice that the other sections concentrate on.

The book can be approached and used in various ways. The chapters are presented in an order which reflects as far as possible the way in which a project develops. You could, therefore, follow it through chapter by chapter with the flow diagram guiding you. However, it is possible to delve into the different chapters and sections as the need or your interest arises. (The sections are as self-contained as possible, with cross-referencing, and a full index is given at the end.) Alternatively, you could read the book through before you start, to give you an overview.

Whatever method you employ, keep sight of the flow diagram and use it to guide you through the different stages of tackling a project. 


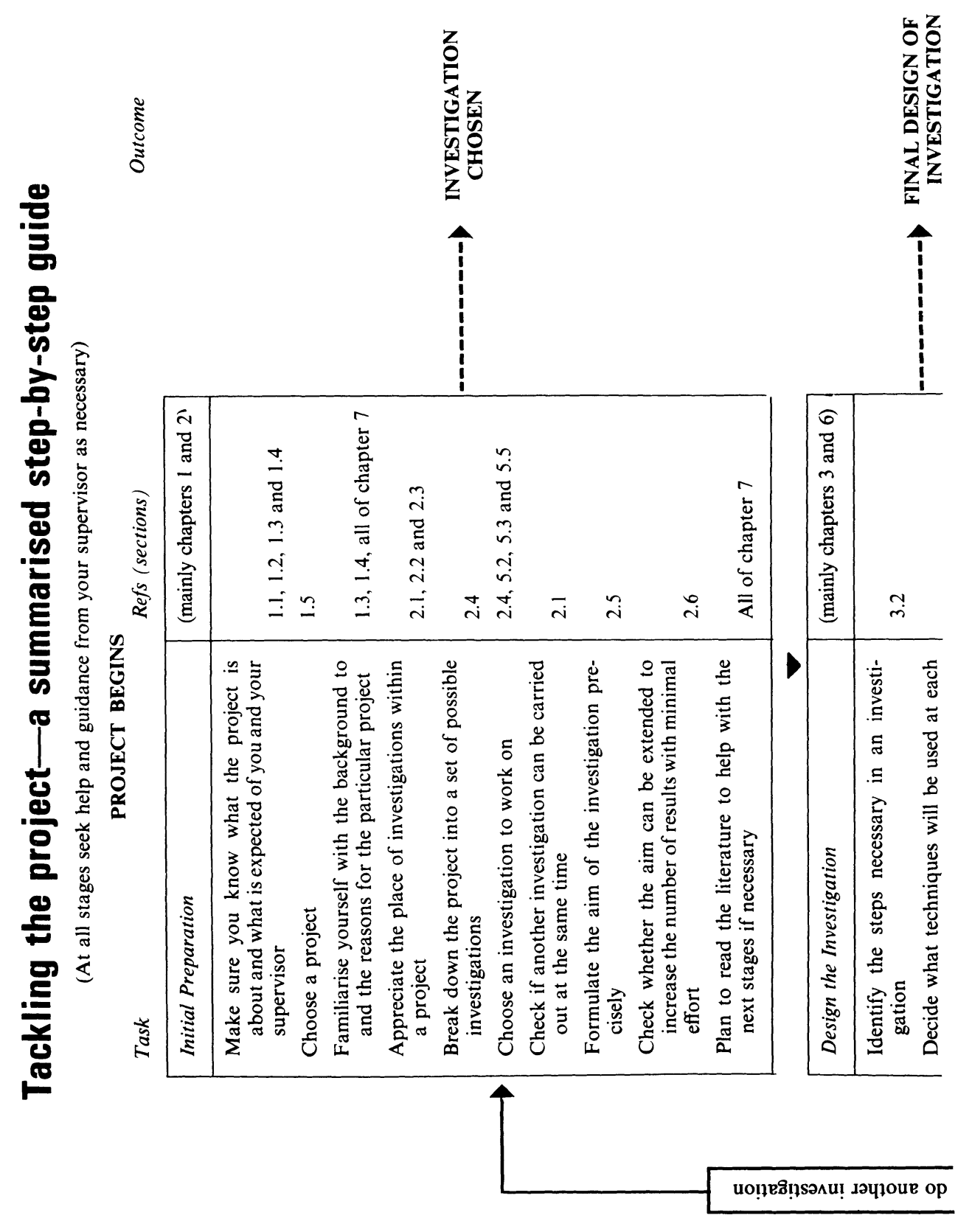




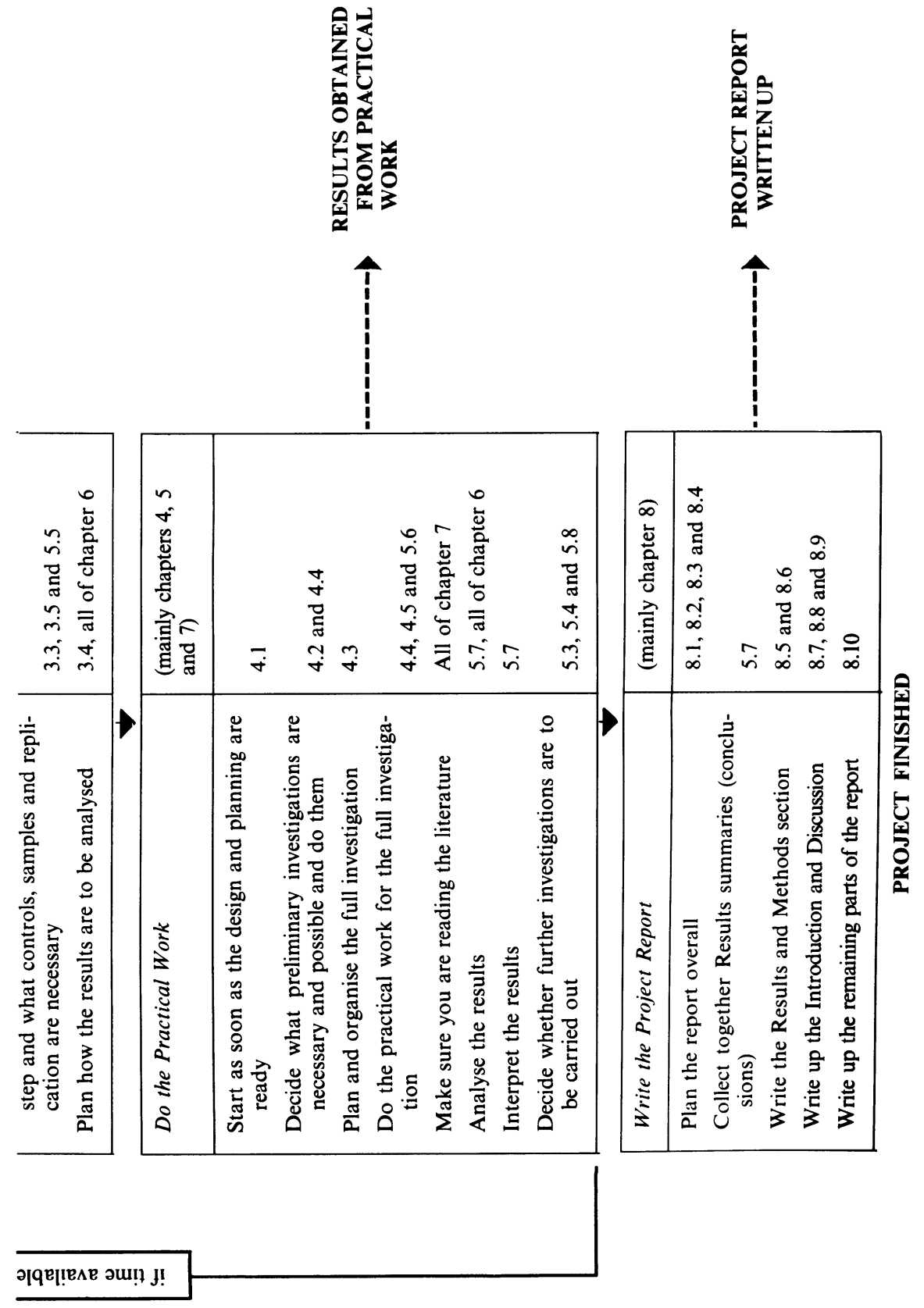

